\title{
Expediciones Botánicas Siglo XXI Aprendiendo Ciencias con José Celestino Mutis.
}

\section{Por: Campos Diego ${ }^{1}$}

Las experiencias con docentes de ciencias nos han permitido conocer como los maestros de diferentes secretarías de Educación enfrentan el reto y compromiso de dar a conocer la diversidad biológica en diferentes contextos, además de contribuir a su uso y conservación. En la gran mayoría de experiencias se evidenció como los valores culturales incluyen saberes que contribuyen a la sensibilización y el reconocimiento de los recursos biológicos en los estudiantes. Por este motivo los profesores del Departamento de Biología, seguimos acompañando experiencias de proyectos de aula con los que se busca estimular el reconocimiento de la diversidad biológica y su uso y conservación a nivel local, regional y nacional así como su aprovechamiento en procesos de enseñanza aprendizaje de la biología y de las ciencias en general en niveles de formación básica y secundaria

\section{CUMARIBO}

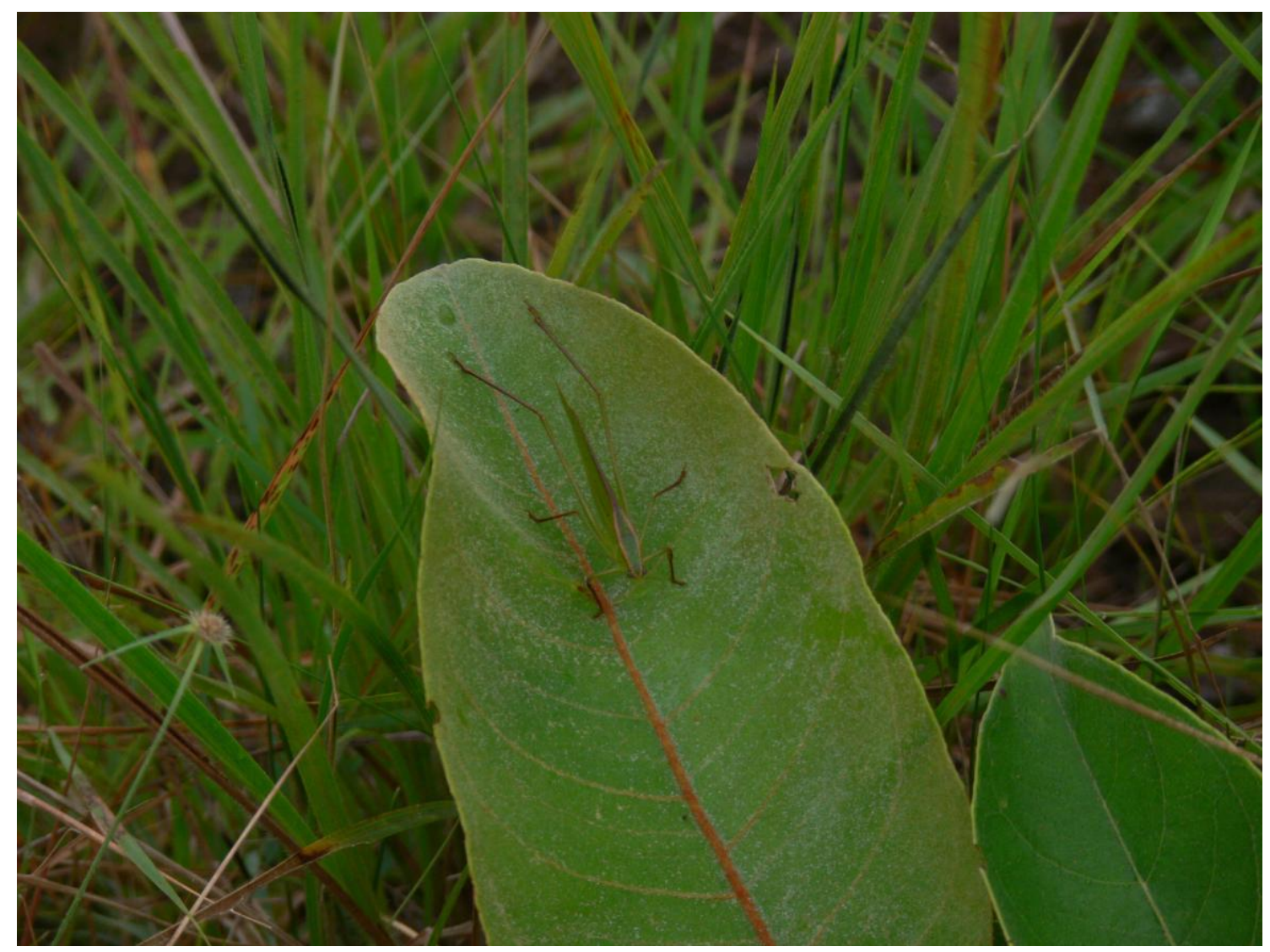

\footnotetext{
${ }^{1}$ Biólogo Universidad Nacional de Colombia. Docente Departamento de Biología Universidad Pedagógica Nacional. Bogotá, Colombia. diego.campos@gmail.com.
} 



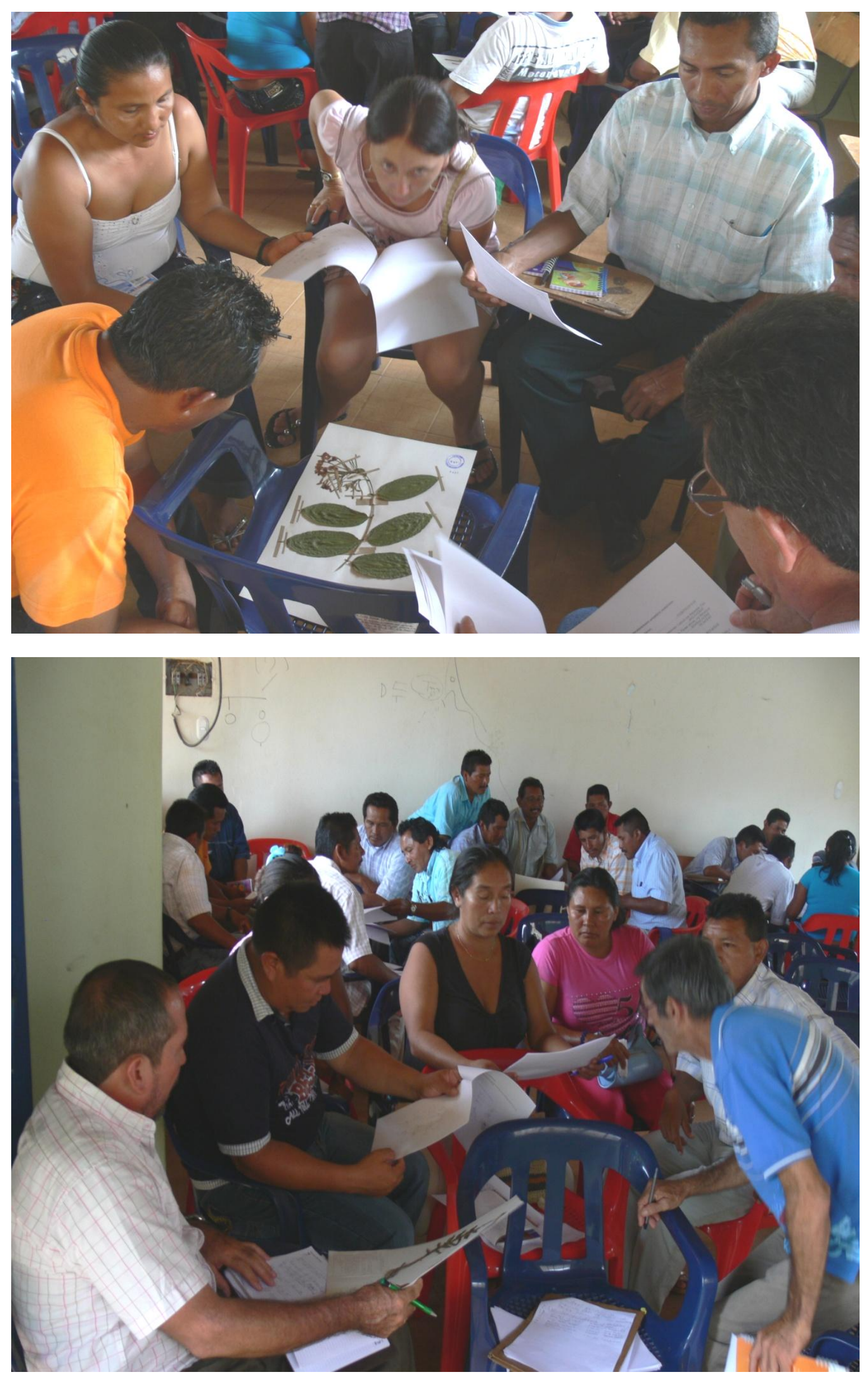

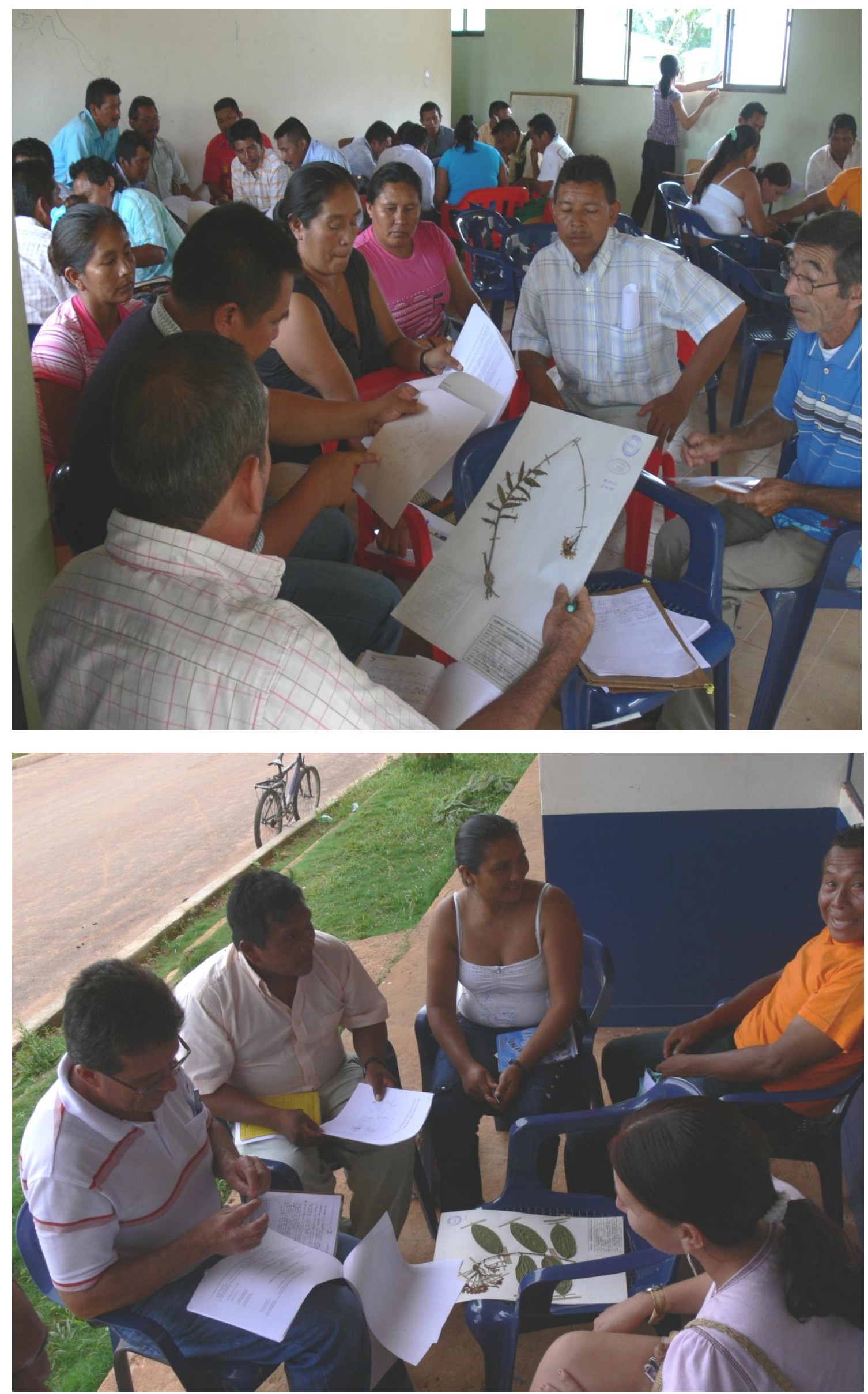

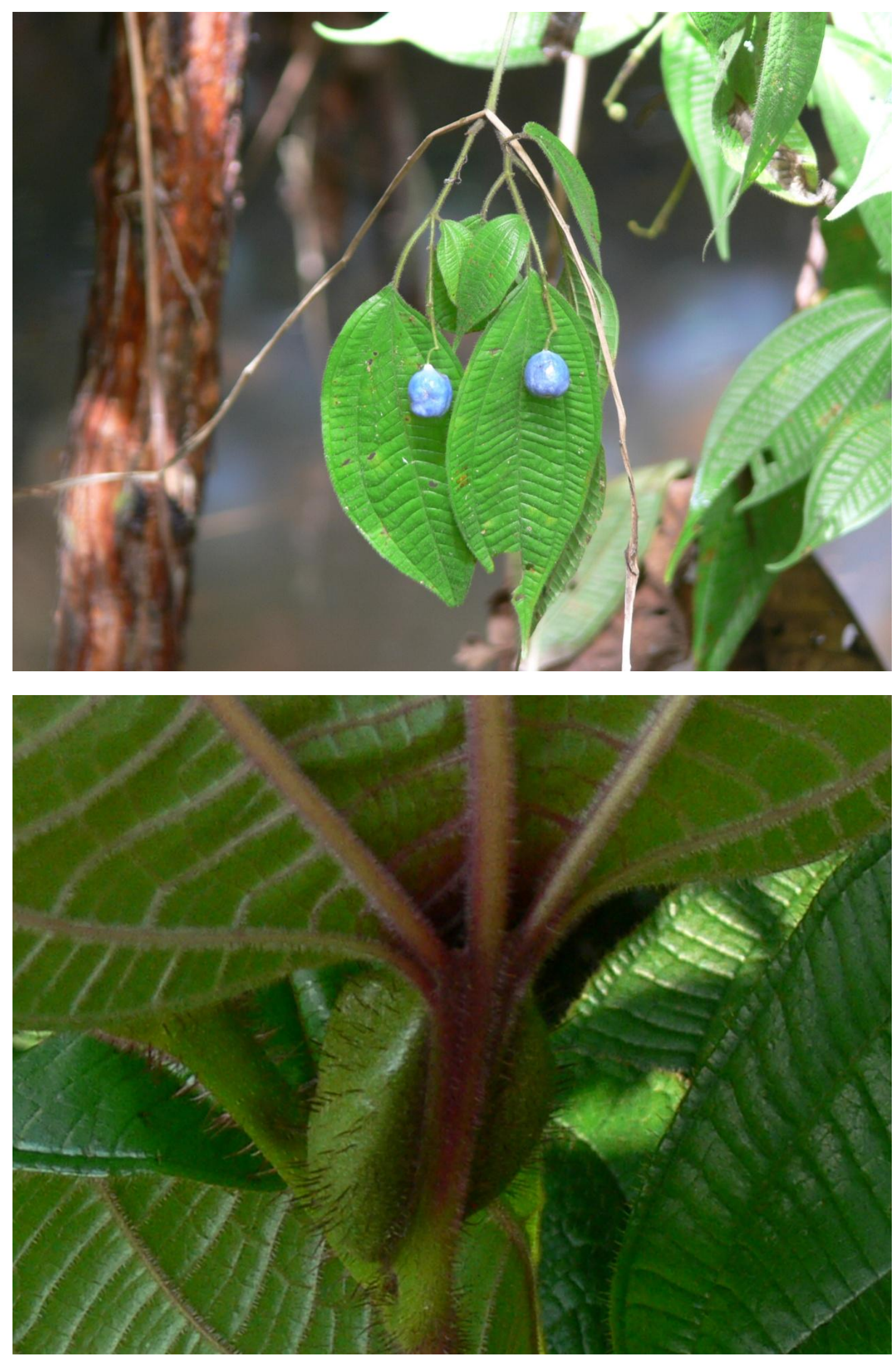


\section{PINILLOS}
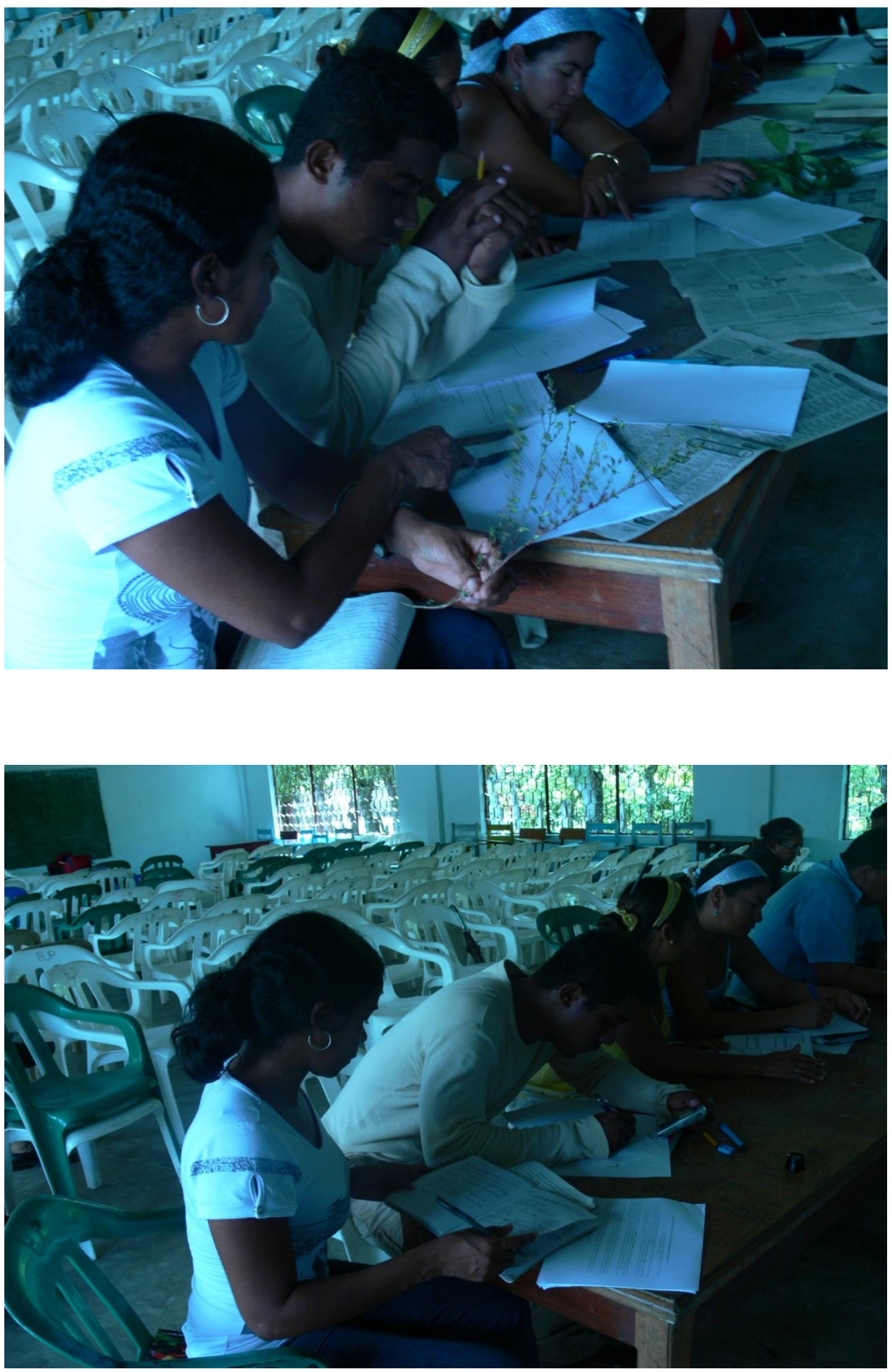

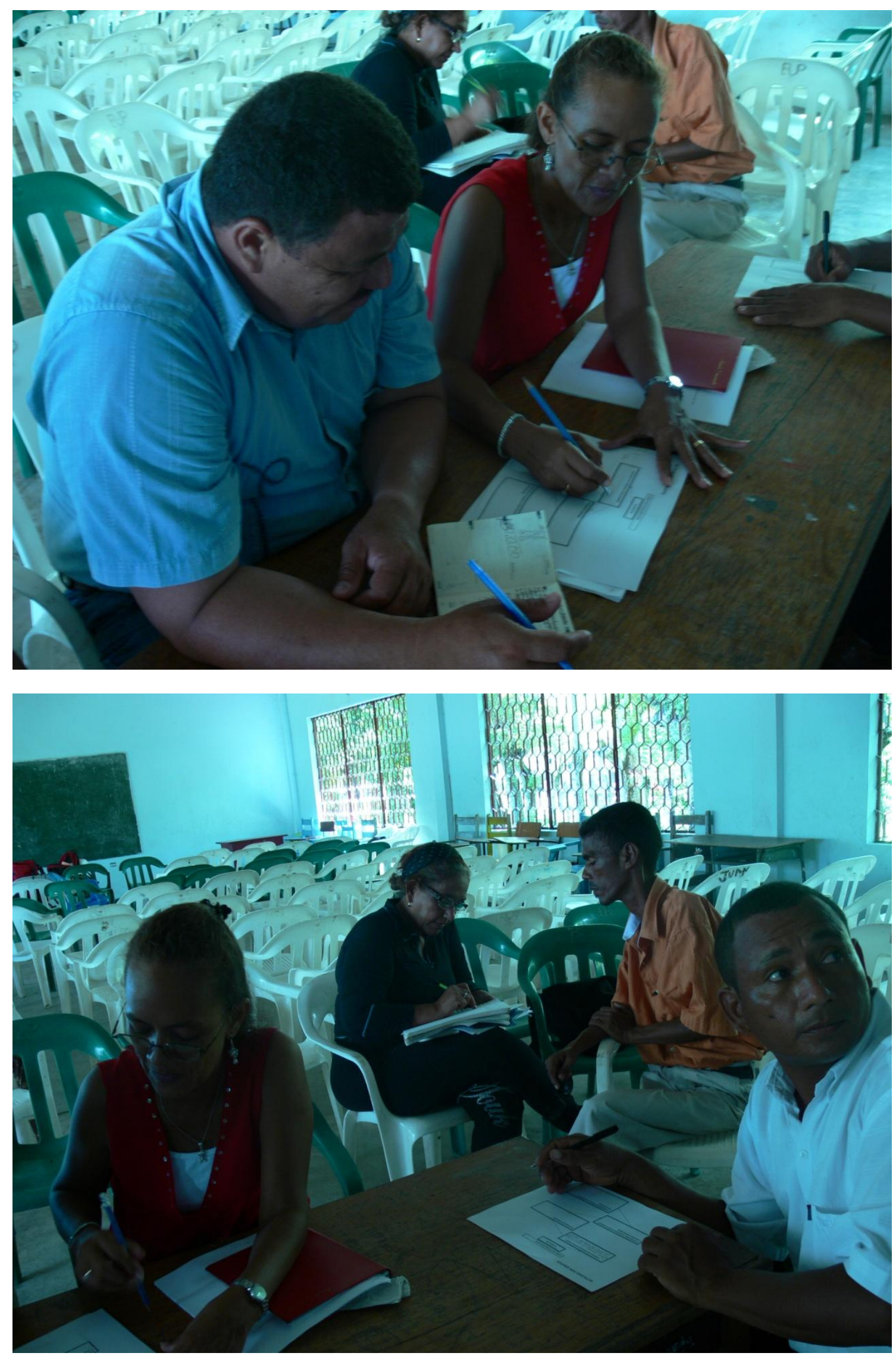


\section{RIO VIEJO}
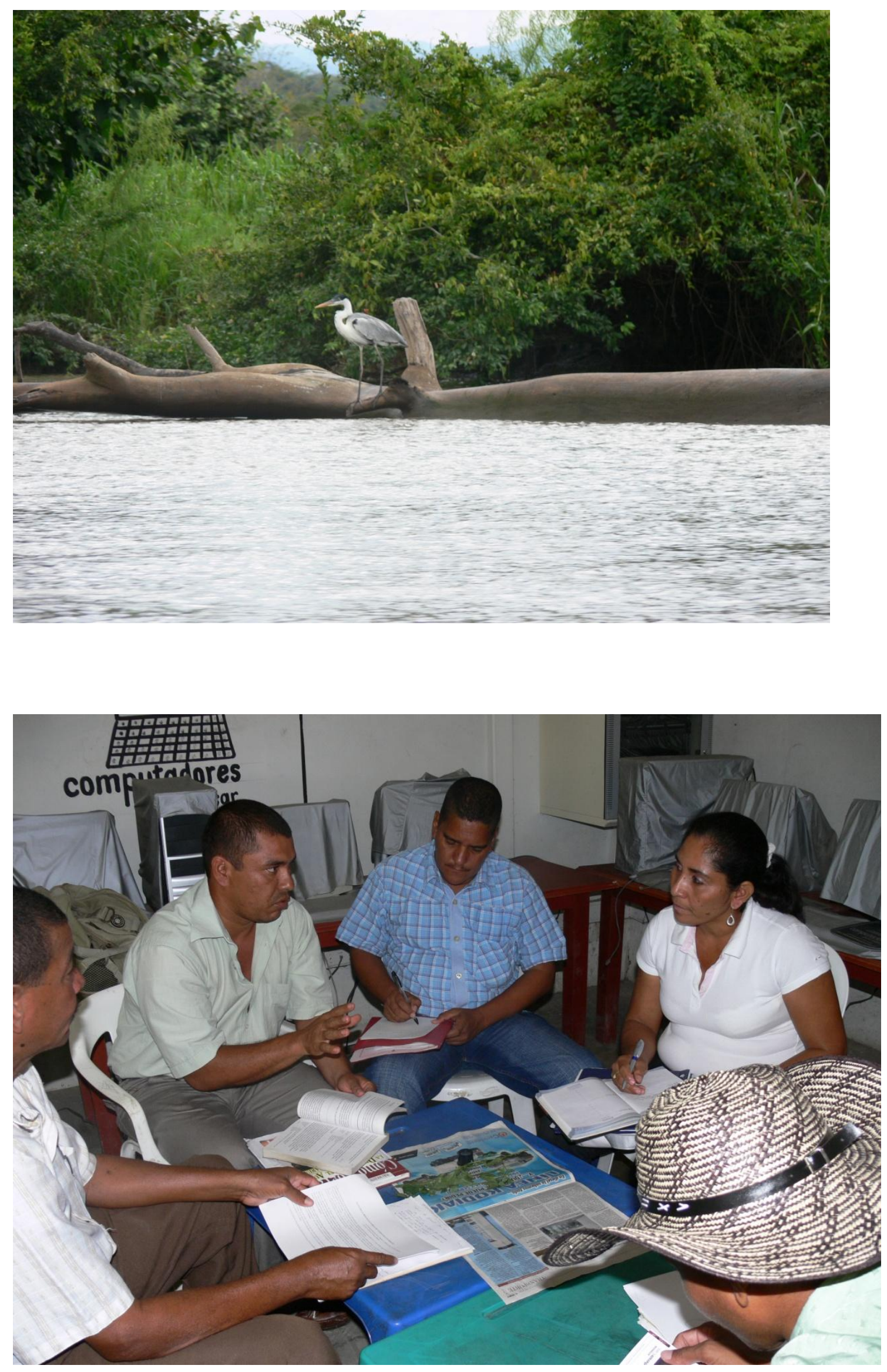

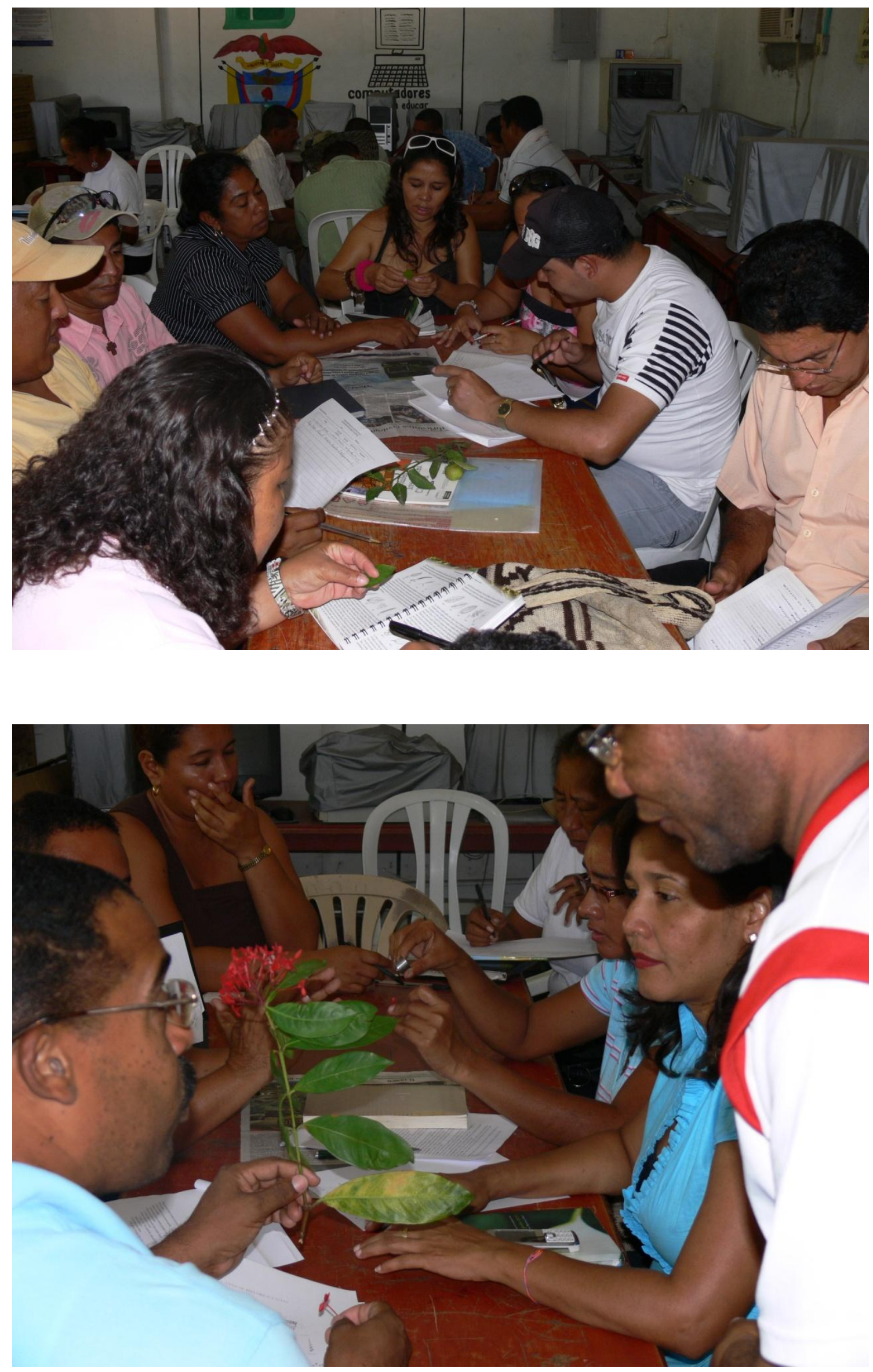


\section{SANTA ROSA DEL SUR}
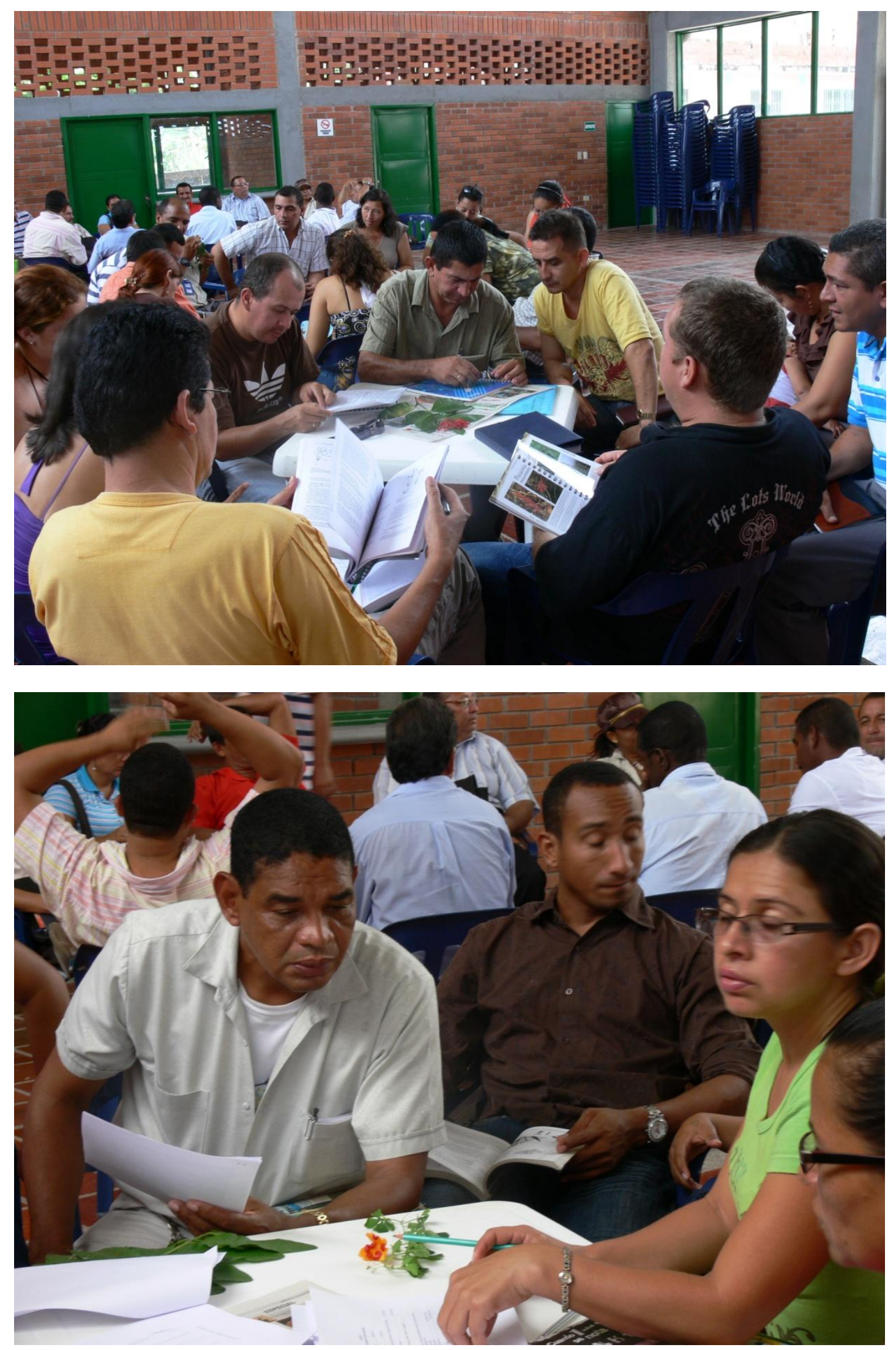

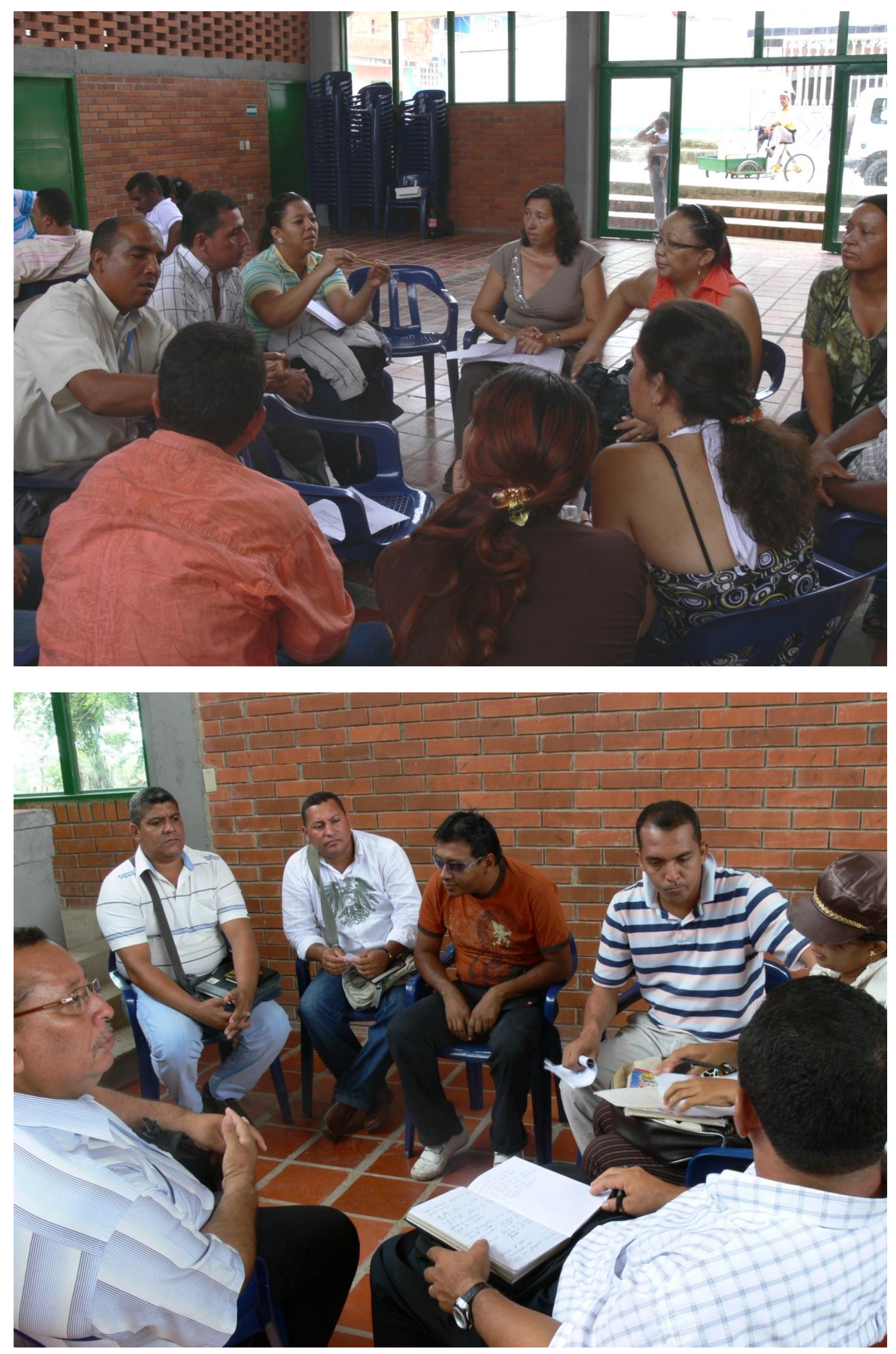

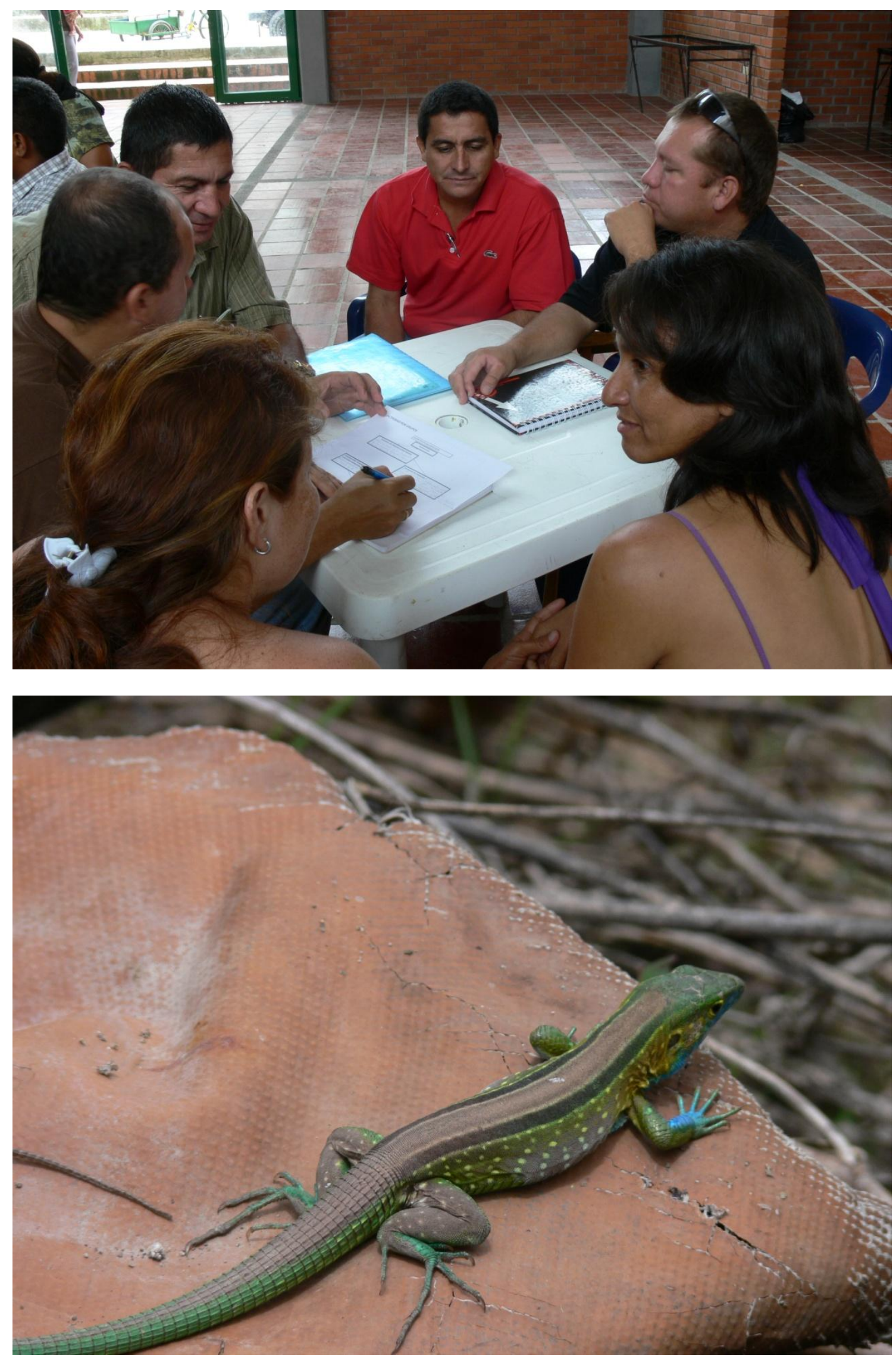